\title{
К ВОПРОСУ О ВЛИЯНИИ ТРУДОВОГО ВОСПИТАНИЯ НА ИСПРАВЛЕНИЕ ЖЕНЩИН, ОСУЖДЕННЫХ К ЛИШЕНИЮ СВОБОДЫ
}

\author{
Н. Б. Лелик
}

Томский институт повышения квалификаџии работников ФСИН России, Томск

Рассматриваются основные формы трудового воспитания, а также вопросы влияния труда на исправление женщин, отбывающих наказания в местах лишения свободы Сибирского и Уральского федеральных округов. Приводятся статистические данные Федеральной службы исполнения наказаний численности женщин, отбывающих наказания в местах лишения свободы, в том числе количество освобожденных из исправительных учреждений за 2018 год. Анализируются результаты проведенного исследования с использованием методов сбора информации, анкетирования и интервьюирования в исправительных колониях общего режима для содержания женщин, ранее отбывавших наказания в местах лишения свободы. Подвергаются анализу нормативные правовые акты уголовно-исполнительного законодательства Российской Федерации, федеральная целевая программа по развитию и дальнейшему совершенствованию уголовно-исполнительной системы, в том числе по созданию дополнительных рабочих мест для осужденных, отбывающих наказания в местах лишения свободы. Кроме того, трактуются изменения в целях привлечения к труду осужденных, отбывающих наказания на участках колонии-поселения исправительного учреждения. Рассматриваются вопросы реализации прав и свобод осужденных женщин в исправительных учреждениях, дальнейшего совершенствования механизма по трудовой занятости, особенно для тех, кто имеет исполнительные документы. Даются рекомендации по использованию методов и приемов трудового воспитания женщин, отбывающих наказания в местах лишения свободы, способствующие прежде всего их исправлению и формированию у них уважительного отношения к человеку, труду, обществу, повышению их образовательного уровня. Таким образом, трудовое воспитание укрепляет чувство собственного достоинства, значимости для ближайшего бытового окружения женщин, ранее отбывавших наказания в исправительных учреждениях.

Ключевые слова: осужденные женщины, труд, трудовое воспитание, средства исправления, уголовно-исполнительная система, исправительные учреждения, исправительные колонии.

Вопросы влияния труда на исправление осужденных к лишению свободы продиктованы интересами уголовно-исполнительного законодательства Российской Федерации, где производительная деятельность в местах лишения свободы должна выполнять основные цели - исправление осужденных и предупреждение совершения ими новых преступлений. Трудовое воспитание по праву считается одним из основных средств исправления осужденных.

На современном этапе при назначении наказания женщинам судами все чаще избирается отсрочка от отбывания наказания или альтернативные меры наказания без изоляции от общества. В связи с чем численность женщин, осужденных к лишению свободы, уменьшается. За 2018 год, по статистическим данным ФСИН России, освобождено из исправительных учреждений 2319 женщин, что привело к сокращению их числа на 5,1% [1]. На протяже- 
нии последних трех лет распространенными преступлениями среди женщин, отбывающих наказания в виде лишения свободы, явились:

- связанные с наркотическими и психотропными средствами (ст. 228-233 УК РФ);

- убийство (ст. 105, 107, 108, 109, 111 ч. 4 УК РФ);

- преступления против собственности (ст. 158, 161, 162, 163 УК РФ).

За последние годы женщин намного чаще, чем мужчин, стали привлекать к уголовной ответственности за распространение наркотических средств. Согласно исследованию А. В. Шеслера, Т. А. Смолиной, причиной повышения такой активности явилась маргинализация женщин в обществе [2].

Исследование, проведенное в 2017-2018 гг. в трех исправительных колониях (ИК) Сибирского и Уральского федеральных округов, посвящено изучению организации трудового воспитания и его влияния на исправление женщин, ранее отбывавших наказание в виде лишения свободы. При проведении исследования применялись следующие методы сбора и анализа информации: формально-юридический (при анализе правовых источников, систематизации нормативных материалов); статистический (при изучении количественных данных); конкретно-социологический (при анкетировании, интервьюировании).

Проводя исследование в исправительных колониях (ИК) Сибирского и Уральского федеральных округов, где содержатся женщины, ранее отбывавшие лишение свободы, выявили, что большинство респондентов находятся в возрасте 26-45 лет (около 70 \%). Данный факт говорит о социально активном возрасте человека, что подтверждается проведенным исследованием, где подавляющее большинство женщин до осуждения были трудоустроены (около 60 \%) в сфере торговли, разнорабочими, а также на различных предприятиях. Трудовая деятельность имеет большое значение в формировании мировоззрения человека и его нравственных взглядов. Как отмечают И. В. Дворянсков и С. А. Злотников, социализация на постпенитенциарном периоде осужденных к лишению свободы будет затруднена, если в исправительных колониях недостаточно хорошо развит производственный сектор, отсутствует возможность выбора с учетом трудоспособности, здоровья и, по возможности, специальности [3, с. 71]. Также известно высказывание А. С. Макаренко о том, что труд без идущего рядом воспитания - нейтральный процесс [4, с. 112]. В связи с этим в исправительных колониях, особенно в таких учреждениях, где отбывают наказание осужденные женщины, создаются условия, которые необходимы для восстановления либо приобретения профессиональных трудовых навыков.

На современном этапе реализуется федеральная целевая программа «Развитие уголовно-исполнительной системы (2018-2026 годы)», одной из задач которой является создание дополнительных рабочих мест для осужденных к лишению свободы [5]. В настоящее время в 37 территориальных органах ФСИН России действуют региональные целевые программы, мероприятия которых направлены на получение мер государственной поддержки. В соответствии с постановлением Правительства Российской Федерации в 70 субъектах РФ получены заказы на поставку продукции для региональных и муниципальных нужд, что позволило дополнительно трудоустроить 1,5 тыс. осужденных [6]. В соответствии с УИК РФ, Федеральным законом РФ от 14 ноября 2002 г. № 161-Ф3 «О государственных и муниципальных унитарных предприятиях», ст. 17 Закона РФ «Об учреждениях и органах, исполняющих уголовные наказания в виде лишения свободы» труд осужденных к лишению свободы, отбывающих наказание в ИУ соответствует следующим формам организации, а именно:

- государственные (федеральные) унитарные производства (компании), размещенные на территориях исправительных учреждений (прилегающих к ИУ режимных территориях); 
- трудовые (центры трудовой адаптации) и производственные мастерские, расположенные на территориях ИУ и на прилегающих режимных территориях;

- предприятия (компании, производства) других организационно-правовых форм, также расположенные на территориях ИУ или вне их, но при условии предоставления надежной охраны этих объектов, обеспечения изоляции осужденных [7];

- организация оплачиваемых работ осужденных по хозяйственному обслуживанию учреждений уголовно-исполнительной системы;

- организация бесплатных работ осужденных по благоустройству учреждений в соответствии со ст. 106 УИК РФ.

В целях привлечения к труду осужденных в местах лишения свободы на базе имущества, предоставляемого в безвозмездное пользование организациями, использующими труд этих осужденных, с 1 января 2020 г. вступили в законную силу изменения ст. 129 УИК РФ по созданию участков колоний-поселений, расположенных вне колоний-поселений, но в пределах субъектов Российской Федерации [8].

На территории Российской Федерации действуют 569 центров трудовой адаптации осужденных, функционируют 75 учебно-производственных и лечебно-производственных мастерских [9]. Согласно ч. 1 ст. 103 УИК РФ, администрация ИУ должна дать возможность трудоустроиться каждому осужденному исходя из наличия рабочих мест. Вместе с тем, согласно ч. 4 ст. 103 УИК РФ, Правил внутреннего распорядка исправительных учреждений (ПВР ИУ), есть перечень работ, на которых запрещено привлекать осужденных, в том числе женщин [10].

Совершенно очевидно, что трудовое воспитание осужденных женщин, отбывавших ранее лишение свободы, должно осуществляться на принципах законности, гуманизма, демократизма, уважения прав человека. Кроме того, трудовое воспитание осужденных женщин в учреждениях уголовно-исполнительной системы должно мотивировать их в дальнейшем трудиться и не совершать новых преступлений [11].

Проведенные исследования в ИК общего режима для содержания женщин, ранее отбывавших лишение свободы, показали, что около 70 \% обеспечены оплачиваемым трудом (женщины пенсионного возраста, а также инвалиды первой или второй группы привлекаются к оплачиваемому труду по желанию), однако нормы выработки на швейном производстве достаточно высокие и низкооплачиваемые. На вопрос «Устраивает ли Вас данная работа?» практически половина респондентов во всех учреждениях ответили отрицательно. Совершенно очевидно, что однообразный, монотонный труд на швейном производстве, который типичен для исправительных колоний, где отбывают наказание осужденные женщины, не устраивает большее количество опрошенных респондентов (около 70 \%). Соответственно, продолжать трудиться по специальности «швея» после освобождения из ИК желают единицы. В связи с этим, на наш взгляд, а также по итогам опроса респондентов, необходимо разнообразить труд осужденных, вводя новые сферы трудовой занятости - вязание (вышивание), занятия народными промыслами (лепка из глины). Женщины, ранее отбывавшие лишение свободы (около 40 \%) указали на необходимость обучения таким профессиям, как кочегар, слесарь, сантехник, штукатур-маляр, сварщик, в связи с тем что они востребованы на рынке труда. Кроме этого, они могли бы трудоустроиться в исправительной колонии, особенно это актуально для тех, кто имеет исполнительные документы. По результатам ранжирования ответов по эффективности применения средств исправления осужденных женщин, ранее отбывавших лишение свободы, во всех учреждениях в тройку наиболее действенных вошли: режим (27\%), оплачиваемый труд (25\%) и воспитательная работа $(21 \%)$, далее - получение общего и профессионального образования (15\%), 
участие в кружковой и досуговой деятельности (8\%) и общественно полезный труд (без оплаты труда) $-4 \%$.

В настоящее время среди осужденных происходит обесценивание труда как сферы самореализации в связи с тем, что труд направлен в основном на получение материальной выгоды, поскольку фактор условно-досрочного освобождения (УДО) и уровень заработной платы являются доминирующими. Так, согласно проведенному исследованию в ИК общего режима для содержания женщин, ранее отбывавших лишение свободы, для большинства респондентов основными мотивирующими факторами трудовой активности являются предоставление УДО (45 \%) и уровень заработной платы (30 \%). Наименее значимыми стимулами выступили: удовлетворение от трудовой деятельности (15\%) и овладение профессией для трудоустройства после освобождения из ИК (10\%). Данные обстоятельства ведут к формированию устойчивой привычки у осужденных женщин трудиться только в период отбывания наказания. В связи с чем утрачивается воспитательное значение труда, что труд это не кара, не средство для времяпрепровождения или способ оплаты государству своего содержания (выплаты по исполнительным листам), это ценность сама по себе, что соответствует биологической потребности развития человека [12, с. 55-58].

Промышленный сектор уголовно-исполнительной системы в настоящее время претерпевает трудности. Однако есть положительная динамика отдельных производств, таких как машиностроение, металлообработка, деревообработка, а вот продукция легкой промышленности, если это не выполнение государственных заказов для министерств, служб и ведомств, остается менее востребованной [10]. Однако швейное производство является основным источником дохода в исправительных учреждениях, где отбывают наказание женщины. Кроме того, в соответствии с ч. 2 ст. 9 УИК РФ, одним из основных средств исправления является общественно полезный труд. Соответственно, роль трудового воспитания обуславливается прежде всего универсальностью и многообразием методов и приемов, которые могут быть использованы в работе по исправлению осужденных женщин, а именно:

- трудовое воспитание направлено на развитие человека, выступает способом затраты его энергии, что в свою очередь отвлекает осужденных женщин от противоправного поведения, является предупреждением совершения ими новых преступлений;

- производительный и квалифицированный труд помогает сохранить осужденным женщинам чувство собственного достоинства во время отбывания наказания, значимость для ближайшего социального окружения в оказании им финансовой поддержки;

- влияние труда на формирование способностей, морально-нравственных, волевых качеств личности человека определяется характером связей осужденной женщины в процессе труда и через труд с другими людьми, укрепляет чувство ответственности, повышает уровень сознательности;

- время привлечения осужденных женщин к оплачиваемому труду засчитывается им в общий трудовой стаж, что является немаловажным фактором при начислении пенсионных выплат;

- трудоустроенные осужденные женщины имеют право на оплачиваемый отпуск, который устанавливается уголовно-исполнительным законодательством РФ длительностью 12 рабочих дней (для воспитательных колоний продолжительность отпуска - 18 рабочих дней), а работающим по своему желанию женщинам в возрасте старше 55 лет либо являющимся инвалидами первой или второй группы отпуск может быть увеличен до 18 рабочих дней;

- за активное участие в воспитательных мероприятиях и добросовестное отношение к труду, обучению к осужденным женщинам в исправительных учреждениях могут 
применяться меры поощрения, а также учитываются при определении степени их исправления.

\section{Список литературы}

1. Характеристика лиц, содержащихся в исправительных колониях для взрослых. URL: http://fsin.su/structure/inspector/ iao/statistika/2018-kharakteristika-lits-soderzhashchikhsya-v-ispravitelnykh-koloniyakh-dlya-vzroslykh.docx (дата обращения: 09.09.2019).

2. Шеслер А. В., Смолина Т. А. Женская преступность, связанная с незаконным оборотом наркотических средств (по материалам Тюменской области). Тюмень: Тюменский юридический институт МВД РФ, 2007. 185 с.

3. Дворянсков И. В., Злотников С. А. Некоторые проблемы совершенствования исполнения наказания в виде лишения свободы в России // Вестник института: преступление, наказание, исправление. 2017. № 2. С. 71.

4. Макаренко А. С. Сочинения. М., 1951. Т. 5. С. 112.

5. О федеральной целевой программе «Развитие уголовно-исполнительной системы (2018-2026 годы)»: постановление Правительства РФ от 06.04.2018 № 420. URL: http://www.pravo.gov.ru (дата обращения: 05.09.2019).

6. Об утверждении перечня товаров (работ, услуг), производимых (выполняемых, оказываемых) учреждениями и предприятиями уголовно-исполнительной системы, закупка которых может осуществляться заказчиком у единственного поставщика (подрядчика, исполнителя): постановление Правительства РФ от 26.12.2013 № 1292 (ред. от 27.06.2016). URL: http://www.pravo.gov.ru (дата обращения: 22.10.2019).

7. Об утверждении примерного Положения о центре трудовой адаптации осужденных или учебно-производственной (трудовой) мастерской учреждения, исполняющего уголовные наказания в виде лишения свободы и Примерного положения о лечебно-производственной (трудовой) мастерской учреждения, исполняющего уголовные наказания в виде лишения свободы: приказ Минюста России от 01.04.2008 № 80. URL: http://www.pravo.gov.ru (дата обращения: 18.10.2019).

8. О внесении изменений в Уголовно-исполнительный кодекс Российской Федерации: Федеральный закон от 18.07.2019 № 179-Ф3. URL: http://www.pravo.gov.ru (дата обращения: 05.09.2019).

9. Концепция федеральной целевой программы «Развитие уголовно-исполнительной системы (2017-2025 годы)»: распоряжение Правительства РФ от 23.12.2016 № 2808-p. URL: http://www.pravo.gov.ru (дата обращения: 02.09.2019).

10. Об утверждении Правил внутреннего распорядка исправительных учреждений: приказ Минюста России от 16.12.2016 № 295 (ред. от 27.06.2019) // Консультант Плюс: справ. правовая система. URL: www.consultant.ru/sys/ (дата обращения: 22.10.2019).

11. Об учреждениях и органах, исполняющих уголовные наказания в виде лишения свободы: закон Российской Федерации от 21.07.1993 № 5473-1 (ред. от 06.02.2019) // Ведомости СНД и ВС РФ. 19.08.1993. № 33. Ст. 1316.

12. Шамсунов С. Х. Некоторые вопросы привлечения к труду осужденных к лишению свободы в современных условиях развития уголовно-исполнительной системы // Вестн. Владимирского юрид. ин-та. 2017. № 2 (43). С. 55-58.

Лелик Наталия Борисовна, кандидат педагогических наук, доцент, полковник внутренней службы, доцент кафедры, Томский институт повышения квалификации работников ФСИН России (ул. Говорова, 10, Томск, Россия, 634057). E-mail: diversha@sibmail.com

Материал поступил в редакциию 25.10.2019.

DOI 10.23951/2307-6127-2020-1-80-86

\section{ON THE INFLUENCE OF LABOR EDUCATION ON THE CORRECTION OF WOMEN, SENTENCED TO IMPRISONMENT}

\section{N. B. Lelik}

Tomsk Institute of Advanced Training of Employees of the Federal Penitentiary Service of Russia, Tomsk, Russian Federation

The article discusses the main forms of labor education, as well as the impact of labor on the lives of women serving sentences in prison in the Siberian and Ural Federal districts. Statistical data of the Federal Penitentiary Service on the number of women serving sentences 
in places of deprivation of liberty, including how many of them have been released from correctional institutions over the past year, are given. The results of the study are analyzed by methods of collecting information, questioning and interviewing in correctional colonies of general regime for the detention of women who previously served imprisonment. The normative legal acts of the criminal executive legislation of the Russian Federation, the federal target program for the development and further improvement of the criminal executive system, including the creation of additional jobs for convicts serving sentences in prison, are analyzed. In addition, the amendments are interpreted in order to attract convicts serving sentences in the areas of the colony-settlement of the correctional institution to work. The issues of realization of the rights and freedoms of convicted women in correctional institutions, further improvement of the mechanism for employment, especially for those who have executive documents, are considered. Recommendations are given on the use of methods and techniques of labor education of women serving sentences in prison, contributing primarily to their correction and the formation of their respectful attitude to the person, work, society, increase their educational level. Thus, labor education strengthens self-esteem, importance for the immediate household environment of women who previously served sentences in correctional institutions.

Keywords: convicted women, labour, labour education, means of correction, penal system, correctional institutions, penal colonies.

\section{References}

1. Kharakteristika lits, soderzhashchikhsya $v$ ispravitel'nykh koloniyakh dlya vzroslykh [Characteristics of persons held in correctional colonies for adults] (in Russian). URL: http://fsin.su/structure/inspectorliao/statistika/2018-kharakteristika-lits-soderzhashchikhsya-v-ispravitelnykh-koloniyakh-dlya-vzroslykh.docx (accessed 9 Oktober 2019).

2. Shesler A. V., Smolina T. A. Zhenskaya prestupnost', svyazannaya s nezakonnym oborotom narkoticheskikh sredstv (po materialam Tyumenskoy oblasti) [Female crime associated with illicit drug trafficking (based on the materials of the Tyumen region)]. Tyumen', Tyumen Law Institute of the Ministry of Internal Affairs of Russia Publ., 2007. 185 p. (in Russian).

3. Dvoryanskov I. V., Zlotnikov S. A. Nekotoryye problemy sovershenstvovaniya ispolneniya nakazaniya v vide lisheniya svobody $\checkmark$ Rossii [Some problems of improving the execution of punishment in the form of imprisonment in Russia]. Vestnik instituta: prestupleniye, nakazaniye, ispravleniye - Bulletin of the Institute: crime, punishment, correction, 2017, no. 2, p. 71 (in Russian).

4. Makarenko A. S. Sochineniya. T. 5 [Compositions. Vol. 5]. Moscow, 1951. P. 112 (in Russian).

5. O federal'noy tselevoy programme "Razvitiye ugolovno-ispolnitel'noy sistemy (2018-2026 gody)": postanovleniye Pravitel'stva RF ot 06.04.2018 no. 420 [About the Federal target program "Development of criminal Executive system (2018-2026)": decree of the Government of the Russian Federation of April 6, 2018 no. 420] (in Russian). URL: http://www.pravo.gov.ru (accessed 5 September 2019).

6. Ob utverzhdenii perechnya tovarov (rabot, uslug), proizvodimykh (vypolnyayemykh, okazyvayemykh) uchrezhdeniyami i predpriyatiyami ugolovno-ispolnitel'noy sistemy, zakupka kotorykh mozhet osushchestvlyat'sya zakazchikom u yedinstvennogo postavshchika (podryadchika, ispolnitelya): postanovleniye Pravitel'stva RF ot 26.12.2013 no. 1292 (red. ot 27.06.2016) [About the approval of the list of the goods (works, services) made (performed, rendered) by establishments and the enterprises of criminal Executive system which purchase can be carried out by the customer at the only supplier (contractor, executor): decree of the Government of the Russian Federation dated December 26, 2013 no. 1292 (revised on June 27, 2016)] (in Russian). URL: http://www.pravo.gov.ru (accessed 22 October 2019).

7. Ob utverzhdenii primernogo Polozheniya o tsentre trudovoy adaptatsii osuzhdennykh ili uchebno-proizvodstvennoy (trudovoy) masterskoy uchrezhdeniya, ispolnyayushchego ugolovnyye nakazaniya $v$ vide lisheniya svobody i Primernogo polozheniya o lechebno-proizvodstvennoy (trudovoy) masterskoy uchrezhdeniya, ispolnyayushchego ugolovnyye nakazaniya $v$ vide lisheniya svobody: prikaz Minyusta Rossii ot 01.04 .2008 no. 80 [On the approval of the model Regulations on the labor adaptation center of convicts or the training and production (labor) workshop of an institution executing criminal sentences in the form of imprisonment and the Model provision on the medical and production (labor) workshop of an institution executing criminal sentences in the form of imprisonment: order of the Ministry of Justice of Russia dated April 1st, 2008 no. 80] (in Russian). URL: http://www.pravo.gov.ru (accessed 18 October 2019). 
8. O vnesenii izmeneniy v Ugolovno-ispolnitel'nyy kodeks Rossiyskoy Federatsii: Federal'nyy zakon ot 18.07.2019 no. 179-FZ [About modification of the Criminal Executive Code of the Russian Federation: Federal Law of July 18, 2019 no. 179-FZ] (in Russian). URL: http://www.pravo.gov.ru (accessed 5 September 2019).

9. Kontseptsiya federal'noy tselevoy programmy "Razvitiye ugolovno-ispolnitel'noy sistemy (2017-2025 gody)": Rasporyazheniye Pravitel'stva RF ot 23.12.2016 no. 2808-r [The concept of the Federal target program "Development of the criminal Executive system (2017-2025)": decree of the Government of the Russian Federation of December 23, 2016 No 2808-p] (in Russian). URL: http://www.pravo.gov.ru (accessed 2 September 2019).

10. Ob utverzhdenii Pravil vnutrennego rasporyadka ispravitel'nykh uchrezhdeniy: prikaz Minyusta Rossii ot 16.12.2016 no. 295 (red. ot 27.06.2019) [About the statement of Rules of internal regulations of correctional institutions: order of the Ministry of Justice of Russia dated December 16, 2016 No 295 (as amended on June 27, 2019)]. Konsul'tant Plyus: sprav. pravovaya sistema [Consultant Plus: legal reference system] (in Russian). URL: www.consultant.ru/sys/ (accessed 22 October 2019).

11. Ob uchrezhdeniyakh $i$ organakh, ispolnyayushchikh ugolovnyye nakazaniya v vide lisheniya svobody: zakon Rossiyskoy Federatsii ot 21.07.1993 no. 5473-1 (red. ot 06.02.2019) [About the institutions and bodies executing criminal punishments in the form of imprisonment: law of the Russian Federation of July 21, 1993 no. 5473-1 (as amended on February 6, 2019)]. Vedomosti SND i VS RF. 19.08.1993, no. 33, article 1316 (in Russian).

12. Shamsunov $S$. H. Nekotoryye voprosy privlecheniya $k$ trudu osuzhdennykh $k$ lisheniyu svobody v sovremennykh usloviyakh razvitiya ugolovno-ispolnitel'noy sistemy [Some questions of employment of persons sentences to deprivation of liberty in modern conditions of development of the penal system]. Vestnik Vladimirskogo yuridicheskogo instituta - Bulletin of Vladimir Law Institute, 2017, no. 2 (43), pp. 55-58 (in Russian).

Lelik N. B., Tomsk Institute of Advanced Training of Employees of the Federal Penitentiary Service of Russia (ul. Govorova, 10, Tomsk, Russian Federation, 634057).

E-mail: diversha@sibmail.com 